\title{
Effects of TSH-suppressive therapy on cardiac morphology and function: beneficial effects of the addition of $\beta$-blockade on diastolic dysfunction
}

\author{
Sevim Gullu, Fevzi Altuntas ${ }^{1}$, Irem Dincer ${ }^{2}$, Cetin Erol $^{2}$ and Nuri Kamel \\ Departments of Endocrinology and Metabolic Diseases, ${ }^{1}$ Internal Medicine and ${ }^{2}$ Cardiology, Ankara University, School of Medicine, Ankara, Turkey \\ (Correspondence should be addressed to S Gullu, Ankara University, School of Medicine, Department of Endocrinology and Metabolic Diseases, \\ Ibn-i Sina Hospital, 10th Floor, D-Block, 06100 Sihhiye, Ankara, Turkey; Email: sevim.gullu@temd.org.tr)
}

\begin{abstract}
Objective: To investigate the effects of long-term levothyroxine (LT4) suppressive therapy on the heart and the effects of $\beta$-blockade on cardiac functions.

Design: Twelve female patients receiving LT4, selected from a group of patients with TSH levels of $0.1-0.4 \mu \mathrm{U} / \mathrm{ml}$, were evaluated. The control group consisted of 11 healthy subjects and 12 patients with TSH levels $<0.05 \mu \mathrm{U} / \mathrm{ml}$.

Methods: Cardiac evaluation consisted of a 12-lead electrocardiogram and an echocardiographic study. Left ventricular mass index (LVMI), isovolumetric relaxation time (IVR), left ventricular end systolic (LVESD) and diastolic diameters, early (VE) and late (VA) diastolic flow velocities and fractional shortening were evaluated. Exercise capacity was assessed with a bicycle ergometer. Both work load and maximal exercise time were measured. Atenolol was given to the patient group at a dosage of $50 \mathrm{mg} /$ day for 3 months and evaluations were repeated.

Results: On basal evaluations, LVMI $\left(96 \pm 17\right.$ vs $\left.78 \pm 21 \mathrm{~g} / \mathrm{m}^{2}\right)$ and IVR $(101 \pm 9$ vs $91 \pm 4 \mathrm{~ms})$ were found to be increased in the patients taking LT4 $(P<0.01)$. LVESD was also lower than controls $(P<0.05)$. A decrease in VE and an increase in VA were also observed in the patients $(P<0.01)$. IVR decreased after atenolol $(92 \pm 10$ vs $101 \pm 9 \mathrm{~ms}, P<0.05)$. LVMI decreased and VE and VA improved but did not reach statistical significance after $\beta$-blockade. Baseline work load and maximal exercise duration were significantly lower in the patients and improvements were observed after atenolol treatment.

Conclusions: These results indicated that cardiac dysfunction may occur even when TSH is suppressed to $0.1-0.4 \mu \mathrm{U} / \mathrm{ml}$ with LT4. $\beta$-blockade improved the cardiac functions.
\end{abstract}

European Journal of Endocrinology 150 655-661

\section{Introduction}

Thyrotoxic patients usually show prominent cardiac manifestations. Coexisting cardiac diseases can be exacerbated by thyrotoxicosis or thyrotoxicosis itself can cause abnormal cardiac function (1-9). Several symptoms and signs of hyperthyroidism, such as palpitations, tremor, tachycardia, nervousness, heat intolerance and sweating mimic the manifestations of $\beta$-adrenergic activity. Many of the clinical features of hyperthyroidism are frequently shared by patients receiving levothyroxine (LT4) suppressive therapy. Suppression of thyroid-stimulating hormone (TSH) by LT4 is used for the treatment of nodular and diffuse non-toxic goiter and postoperative treatment of differentiated thyroid carcinoma $(10,11)$. Some reports have described the cardiac effects of chronic LT4 treatment at doses that result in minimal thyroid hormone excess defined by suppression of TSH (12-18) but not in all (19). An increased incidence of symptoms suggesting adrenergic overactivity, significant increases in mean basal heart rate and atrial premature contractions, enhanced left ventricular (LV) systolic function and increased LV mass, and abnormalities in ventricular diastolic relaxation and exercise capacity have been reported in patients receiving suppressive doses of LT4 $(12-14)$. The reversal of symptoms of thyrotoxicosis and improvement in cardiac abnormalities found in symptomatic patients were reported with $\beta$-adrenergic blockade $(15,16)$.

Increasing evidence supports the existence of $\mathrm{LV}$ diastolic dysfunction as an important cause of congestive heart failure and impairment in systolic performance especially during physical exercise $(20-25)$.

In previous studies, patients with TSH levels that were either undetectable or below $0.1 \mu \mathrm{U} / \mathrm{ml}$ were included. A TSH suppression of $0.1-0.4 \mu \mathrm{U} / \mathrm{ml}$ has been accepted as the target for the treatment of nodular goiter and the 
effects of LT4 on cardiac functions in these patients have not been evaluated previously. The aim of this study was to evaluate the effects of long-term LT4 suppressive treatment on cardiac functions in patients with a TSH level between 0.1 and $0.4 \mu \mathrm{U} / \mathrm{ml}$. The effect and efficacy of a cardioselective $\beta$-adrenergic blocker on cardiac functions were also evaluated.

\section{Subjects and methods}

\section{Subjects}

Twelve patients, all women, who had been under LT4 treatment (Levotiron, Abdi Ilbrahim Ilac San, Istanbul, Turkey) for at least 2 years for nodular or diffuse goiter were included in the study (study group). These patients were selected from a group of patients since they had had TSH levels between 0.1 and $0.4 \mu \mathrm{U} / \mathrm{ml}$ for at least 6-12 months in at least two measurements prior to and at the beginning of the study. The mean age was $40 \pm 6$ years (range 30-46 years) and the mean LT4 dosage was $117 \pm 23 \mu \mathrm{g} /$ day. The presence of latent coronary disease was excluded by thallium201 myocardial scintigraphy in the patient group. Eleven age- and body mass index (BMI: body weight $(\mathrm{kg}) /$ height $\left.\left(\mathrm{m}^{2}\right)\right)$-matched healthy normal subjects (mean age $37 \pm 5$, range $30-45$ years) were selected as control group 1 , and 12 patients who were also taking LT4 with TSH levels $<0.05 \mu \mathrm{U} / \mathrm{ml}$ served as control group 2 . None of the patients was taking any medication, apart from LT4, that may affect the thyroid function tests or that may interfere with cardiovascular results during the study. All subjects gave informed consent before participating in the study and the protocol was approved by the local ethical committee.

Systolic and diastolic cardiac functions were evaluated in all groups. Electrocardiogram was performed on each patient. Blood pressure, pulse rate and pressure, and other clinical symptoms and signs of the patients were evaluated and recorded just before the morning dosage of LT4. All parameters were also assessed in the control groups. Atenolol, a cardioselective $\beta$-adrenergic blocker, was added to the LT4 therapy of the study group at a dosage of $50 \mathrm{mg} /$ day for 3 months. Clinical, hormonal and cardiac evaluations were repeated in the study group after the treatment period. Blood samples for hormonal analysis were taken at $0800 \mathrm{~h}$, in order to exclude normal diurnal TSH variation, on 2 consecutive days and the mean of the two measurements was used for statistical evaluations. Cardioselective $\beta$-adrenergic blockade (atenolol) was well tolerated by the patients. No side-effects were observed.

\section{Hormonal assays}

Evaluation of serum free tri-iodothyronine (FT3), free thyroxine (FT4) and TSH levels were performed with commercially available automated chemiluminescence system kits (ACS:180; Chiron Diagnostics, Medfield, MA, USA). The kit used for TSH measurement was a third generation assay kit with a lower detectable limit of $0.011 \mu \mathrm{U} / \mathrm{ml}$. The inter- and intra-assay coefficient of variation of each assay was less than $7 \%$. The normal ranges of the hormones were: TSH, 0.45.0 $\mu \mathrm{U} / \mathrm{ml}$; FT3, 3.3-7.5 pmol/l; FT4,10-24 pmol/l.

\section{Electrocardiogram and echocardiography examination}

A standard 12-lead electrocardiogram was performed on each patient. Complete M-mode, two-dimensional studies and spectral Doppler-echocardiographic evaluations were performed by using an ultrasound mechanical system equipped with $2.5 \mathrm{MHz}$ transducer (sonos 1000 ultrasound imaging system; HewlettPackard, Andover, MA, USA). All measurements were made with the subject in the left lateral decubitus position. LV dimensions were measured by M-mode at the systole and diastole ends. All M-mode measurements were made according to the recommendations of the American Society of Echocardiography (26). LV mass was calculated using the following equation (27): $\mathrm{LV}$ mass $=1.04((\mathrm{IVST}+$ $\left.\left.\mathrm{LVID}^{+} \mathrm{PWT}\right)^{3}-(\mathrm{LVID})^{3}\right)-13.6$, where LVID is LV dimension, IVST is interventricular septal thickness and PWT is posterior wall thickness.

$\mathrm{LV}$ mass was indexed by body surface area (LVMI, $\left.\mathrm{g} / \mathrm{m}^{2}\right)$. LV mass, ejection fraction, LV end diastolic dimension (LVEDD, $\mathrm{mm}$ ) and end systolic dimension (LVESD, mm), early diastolic flow velocity (VE) and late diastolic flow velocity (VA), VE/VA ratio and isovolumetric relaxation time (IVR) were assessed in both controls and patients.

\section{Exercise capacity}

Maximal exercise capacity was assessed with a bicycle ergometer (Ergomed 740; Siemens-Elema, Solna, Sweden). Exercise load was increased $25 \mathrm{~W}$ every $2 \mathrm{~min}$. The test was stopped when severe fatigue, weakness or dyspnea occurred. Continuous electrocardiogram monitorization was performed during the test. Blood pressure and heart rate were measured every 2 min.

\section{Statistical analysis}

Data are given as the means \pm S.D. The significance of differences between patients and controls was assessed by the unpaired $t$-test, whereas the effects of $\beta$-blockade were processed by paired analysis. $P<0.05$ was accepted as significant. Mann-Whitney U test was used when necessary. Correlations between parameters were determined by Pearson correlation analysis. 


\section{Results}

Clinical and laboratory characteristics of the control groups and the study group receiving long-term LT4 suppressive treatment are given in Table 1. All controls and the study group were female and there were no differences between ages and BMI between the study and control groups.

\section{Thyroid hormones}

Mean serum FT4 levels were significantly higher in the study group and control group 2 than in the normal subjects (control 1) and the mean serum TSH level was significantly higher in control group 1 than in the patients (Table 1 ). No statistically significant difference was observed in the hormone levels after 3 months of $\beta$-adrenergic blockade with atenolol in the study group. Although a slight decrease in FT3 levels and a slight increase in FT4 levels were observed after atenolol, they did not reach statistical significance (Table 1).

\section{Cardiac functions}

Data are given in Table 2.

Study group vs normal subjects LVMI was higher in the study group than in control group $1(96 \pm 17$ vs $\left.78 \pm 21 \mathrm{~g} / \mathrm{m}^{2}, P<0.01\right)$. IVR was found to be increased in the patients compared with the controls $(101 \pm 9$ vs $91 \pm 4 \mathrm{~ms}, P<0.01)$. The LVESD was also lower in patients taking suppressive doses of LT4 $(P<0.05)$. VE was decreased $(0.72 \pm 0.12$ vs $0.96 \pm 0.16 \mathrm{~m} / \mathrm{s}$, $P<0.01)$ and VA was increased $(0.72 \pm 0.23$ vs $0.65 \pm 0.1 \mathrm{~m} / \mathrm{s}, P<0.01)$ in the patient group. The VE/VA ratio was lower in the patient group $(0.94 \pm 0.19$ vs $1.06 \pm 0.28, P<0.01)$. Fractional shortening (FS) and LVEDD were not different between controls and patients. There was a positive correlation between LVMI and VA $(r=0.56, P<0.01)$ and negative correlation between LVMI and VE $(r=0.48, P<0.01)$.

Study group vs patients with TSH $<0.05 \mu \mathrm{U} / \mathrm{mI}$ LVMI was higher in the patients with TSH $<0.05 \mu \mathrm{U} / \mathrm{ml}$ (control group 2) than in the study

Table 1 Clinical and laboratory characteristics of the control subjects and the study group receiving long-term LT4 suppressive treatment before and after $\beta$-blockade. Values are means \pm S.D.

\begin{tabular}{|c|c|c|c|c|}
\hline & \multirow[b]{2}{*}{$\begin{array}{c}\text { Control } 1 \\
\text { (normal subjects) }\end{array}$} & \multirow[b]{2}{*}{$\begin{array}{c}\text { Control } 2 \\
(\mathrm{LT} 4, \mathrm{TSH}<0.05 \mu \mathrm{U} / \mathrm{ml})\end{array}$} & \multicolumn{2}{|c|}{ Study group } \\
\hline & & & $\begin{array}{c}\mathrm{LT} 4, \mathrm{TSH} \\
0.1-0.4 \mu \mathrm{U} / \mathrm{ml}\end{array}$ & $\begin{array}{l}\text { LT4 + atenolol } 50 \mathrm{mg} \text {, } \\
\text { TSH } 0.1-0.4 \mu \mathrm{U} / \mathrm{ml}\end{array}$ \\
\hline Number & 11 & 12 & 12 & 12 \\
\hline Sex & All female & All female & All female & All female \\
\hline Age (years) & $37 \pm 5$ & $41 \pm 4$ & $40 \pm 6$ & $40 \pm 6$ \\
\hline BMI $\left(\mathrm{kg} / \mathrm{m}^{2}\right)$ & $23 \pm 2$ & $23 \pm 4$ & $22 \pm 3$ & $22 \pm 3$ \\
\hline LT4 doses ( $\mu \mathrm{g} /$ day) & & $135 \pm 15 \ddagger$ & $117 \pm 23$ & $117 \pm 23$ \\
\hline Duration of treatment (years) & & $>2$ & $>2$ & $>2$ \\
\hline FT3 $(\mathrm{pmol} / \mathrm{l})$ & $4.7 \pm 0.9$ & $5.1 \pm 0.7$ & $4.8 \pm 0.56$ & $4.4 \pm 0.96$ \\
\hline FT4 (pmol/l) & $16.1 \pm 2.1$ & $20.9 \pm 2.7^{*}$ & $21.3 \pm 3.7^{\star}$ & $22.4 \pm 2.9^{\star}$ \\
\hline $\mathrm{sTSH}(\mu \mathrm{U} / \mathrm{ml})$ & $1.2 \pm 0.4$ & $<0.05^{\star} † \ddagger$ & $0.21 \pm 0.03^{\star}$ & $0.22 \pm 0.02^{*}$ \\
\hline
\end{tabular}

sTSH, sensitive TSH.

${ }^{\star} P<0.01$ compared with controls, $† P<0.001$ compared with controls, $¥ P<0.01$ between control 2 and study group.

Table 2 Resting echocardiographic findings of the controls and the study group. Values are means \pm S.D.

\begin{tabular}{|c|c|c|c|c|c|}
\hline & $\begin{array}{c}\text { Control 1 } \\
(n=11)\end{array}$ & $\begin{array}{c}\text { Control } 2 \\
(\mathrm{LT} 4, \mathrm{TSH}<0.05 \mu \mathrm{U} / \mathrm{ml}) \\
(n=12)\end{array}$ & $\begin{array}{c}\text { Study group } \\
(\mathrm{LT} 4, \mathrm{TSH} 0.1-0.4 \mu \mathrm{U} / \mathrm{ml}) \\
(n=12)\end{array}$ & $P_{\mathrm{a}}$ & $P_{\mathrm{b}}$ \\
\hline LVMI $\left(\mathrm{g} / \mathrm{m}^{2}\right)$ & $78 \pm 21$ & $105 \pm 19$ & $96 \pm 17$ & $<0.01$ & $<0.05$ \\
\hline FS (\%) & $40 \pm 0.94$ & $42 \pm 4.13$ & $41 \pm 3.21$ & NS & NS \\
\hline IVR (ms) & $91 \pm 4$ & $104 \pm 8$ & $101 \pm 9$ & $<0.01$ & $<0.05$ \\
\hline LVESD (mm) & $28 \pm 3$ & $26 \pm 4$ & $27 \pm 5$ & $<0.05$ & NS \\
\hline LVEDD (mm) & $46 \pm 2$ & $44 \pm 3$ & $45 \pm 5$ & NS & NS \\
\hline $\operatorname{VE}(\mathrm{m} / \mathrm{s})$ & $0.96 \pm 0.16$ & $0.68 \pm 0.11$ & $0.72 \pm 0.12$ & $<0.01$ & $<0.05$ \\
\hline $\mathrm{VA}(\mathrm{m} / \mathrm{s})$ & $0.65 \pm 0.1$ & $0.77 \pm 0.14$ & $0.72 \pm 0.23$ & $<0.01$ & $<0.05$ \\
\hline VE/VA & $1.54 \pm 0.25$ & $0.94 \pm 0.19$ & $1.06 \pm 0.28$ & $<0.01$ & $<0.05$ \\
\hline
\end{tabular}

FS, fractional shortening.

$P_{\mathrm{a}}$ baseline significant value from control $1 ; P_{\mathrm{b}}$ significant values between control 2 and study group; NS, not significant. 
group (105 \pm 19 vs $\left.96 \pm 17 \mathrm{~g} / \mathrm{m}^{2}, P<0.05\right)$. IVR was also higher in control group 2 than in the study group $(104 \pm 8$ vs $101 \pm 9 \mathrm{~ms}, \quad P<0.05)$. VE was lower $(0.68 \pm 0.11$ vs $0.72 \pm 0.12 \mathrm{~m} / \mathrm{s}, P<0.05)$ and VA was higher $(0.77 \pm 0.14$ vs $0.72 \pm 0.23 \mathrm{~ms}$, $P<0.05)$ and the VE/VA ratio was lower in control group $2(0.94 \pm 0.19$ vs $1.06 \pm 0.28, P<0.01)$ than in the study group. FS and LVESD and LVEDD were not different between the study group and control group 2.

Study group before and after $\boldsymbol{\beta}$-blockade Results are given in Table 3. FS did not change with adrenergic $\beta$-blockade. LVMI decreased with the addition of atenolol but it did not reach statistical significance. IVR decreased with the $\beta$-blockade therapy (92 10 vs $101 \pm 9 \mathrm{~ms}, P<0.05)$. Although improvements in VE, VA and VE/VA ratio were observed with atenolol therapy, these did not reach statistical significance. FS, LVESD and LVEDD did not change after atenolol.

\section{Exercise capacity}

Data are given in Table 4.
Study group vs control group 1 (normal subjects) Mean basal systolic and diastolic blood pressures were not different in patients taking LT4 and controls. The basal heart rate of the patients who were taking LT4 was higher than the controls ( $88 \pm 5$ vs $76 \pm 7$ beats/ min, $P<0.05)$, but the maximal heart rate at maximal exercise was not different from the controls (167 \pm 7 vs $172 \pm 14$ beats/min). The baseline mean maximal exercise time was significantly lower in the patient group than the controls $(7 \pm 1.89$ vs $11.3 \pm 1.57 \mathrm{~min}$, $P<0.001)$. The baseline peak work load was also lower in the patient group $(87 \pm 23$ vs $141 \pm 19 \mathrm{~W}$, $P<0.001)$.

Study group vs control group 2 (patients with TSH $<0.05 \mu \boldsymbol{U} / \mathbf{m l})$ The basal heart rate of the study group was lower than control group $2(92 \pm 4$ vs $88 \pm 5$ beats/min, $P<0.05$ ), but the mean maximal heart rate at maximal exercise was not different between groups. The mean basal systolic blood pressure was higher in control group 2 than the study group. The baseline mean maximal exercise time was significantly higher in the study group $(7 \pm 1.89$ vs $6.2 \pm 1.71 \mathrm{~min}$, $P<0.05)$. The baseline peak work load was also higher in the study group $(87 \pm 23$ vs $80 \pm 20 \mathrm{~W}$, $P<0.01)$.

Table 3 Resting echocardiographic findings of the study group $(n=12)$ before and after $\beta$-blockade. Values are means \pm S.D.

\begin{tabular}{lccc}
\hline & Before & After & \\
& LT4, TSH $0.1-0.4 \mu \mathrm{U} / \mathrm{ml}$ & LT4 + atenolol, TSH $0.1-0.4 \mu \mathrm{U} / \mathrm{ml}$ & $\boldsymbol{P}$ \\
\hline LVMI $\left(\mathrm{g} / \mathrm{m}^{2}\right)$ & $96 \pm 17$ & $88 \pm 16$ & $\mathrm{NS}$ \\
FS $(\%)$ & $41 \pm 3.21$ & $40 \pm 2.6$ & $\mathrm{NS}$ \\
IVR $(\mathrm{ms})$ & $101 \pm 9$ & $92 \pm 10$ & $\mathrm{NS}$ \\
LVESD $(\mathrm{mm})$ & $27 \pm 5$ & $27 \pm 4$ & $\mathrm{NS}$ \\
LVEDD $(\mathrm{mm})$ & $45 \pm 5$ & $46 \pm 6$ & $\mathrm{NS}$ \\
VE $(\mathrm{m} / \mathrm{s})$ & $0.72 \pm 0.12$ & $0.79 \pm 0.2$ & $\mathrm{NS}$ \\
VA $(\mathrm{m} / \mathrm{s})$ & $0.72 \pm 0.23$ & $0.69 \pm 0.12$ & $\mathrm{NS}$ \\
VE $/$ NA & $1.06 \pm 0.28$ & $1.15 \pm 0.27$ & \\
\hline
\end{tabular}

NS, not significant.

Table 4 Exercise capacity parameters in controls and study group receiving LT4 therapy. Values are means \pm S.D.

\begin{tabular}{|c|c|c|c|c|c|c|}
\hline & $\begin{array}{c}\text { Control } 1 \\
(n=11)\end{array}$ & $\begin{array}{c}\text { Control } 2 \\
(\mathrm{LT} 4, \mathrm{TSH}<0.05 \mu \mathrm{U} / \mathrm{ml}) \\
(n=12)\end{array}$ & $\begin{array}{c}\text { Study group } \\
(\mathrm{LT} 4, \mathrm{TSH} 0.1-0.4 \mu \mathrm{U} / \mathrm{ml}) \\
(n=12)\end{array}$ & $P_{\mathrm{a}}$ & $P_{\mathrm{b}}$ & $P_{\mathrm{c}}$ \\
\hline \multicolumn{7}{|l|}{ Resting } \\
\hline Heart rate (beat/min) & $76 \pm 7$ & $92 \pm 4$ & $88 \pm 5$ & $<0.01$ & $<0.05$ & $<0.05$ \\
\hline Systolic blood pressure (mmHg) & $126 \pm 13$ & $132 \pm 14$ & $126 \pm 17$ & $<0.05$ & NS & $<0.05$ \\
\hline Diastolic blood pressure $(\mathrm{mmHg})$ & $74 \pm 8$ & $80 \pm 4$ & $81 \pm 6$ & NS & NS & NS \\
\hline \multicolumn{7}{|l|}{ Maximal exercise } \\
\hline Heart rate (beat/min) & $172 \pm 14$ & $165 \pm 8$ & $167 \pm 7$ & $<0.01$ & $<0.01$ & NS \\
\hline Systolic blood pressure (mmHg) & $167 \pm 11$ & $156 \pm 13$ & $153 \pm 16$ & $<0.01$ & $<0.01$ & NS \\
\hline Diastolic blood pressure $(\mathrm{mmHg})$ & $78 \pm 5$ & $84 \pm 5$ & $85 \pm 4$ & NS & NS & NS \\
\hline Work load (W) & $141 \pm 19$ & $80 \pm 20$ & $87 \pm 23$ & $<0.001$ & $<0.001$ & $<0.01$ \\
\hline Exercise time (min) & $11.3 \pm 1.57$ & $6.2 \pm 1.71$ & $7 \pm 1.89$ & $<0.001$ & $<0.001$ & $<0.05$ \\
\hline
\end{tabular}

$P_{\mathrm{a}}$, difference between controls and patients with TSH $<0.05 \mu \mathrm{U} / \mathrm{ml} ; P_{\mathrm{b}}$, difference between controls and patients with TSH $0.1-0.4 \mu \mathrm{U} / \mathrm{ml} ; P_{\mathrm{c}}$, difference between study group and control 2; NS, not significant. 
Study group before and after $\beta$-blockade Data are given in Table 5. $\beta$-adrenergic blockade (atenolol) decreased both the basal and maximal exercise heart rates $(P<0.005$ and $P<0.01$ respectively $)$. The mean maximal exercise time increased from $7 \pm 1.89$ to $8.6 \pm 1.6 \mathrm{~min}$ with $\beta$-adrenergic blockade (atenolol, $P=0.007)$. The baseline peak work load was increased from $87 \pm 23$ to $111 \pm 19 \mathrm{~W}$ with the atenolol treatment $(P=0.0079)$. Systolic and diastolic blood pressures were also decreased after atenolol.

\section{Electrocardiographic examinations}

No arrhythmia was observed in controls and patients during electrocardiogram monitoring.

\section{Discussion}

The main finding of this study, which covered a group of patients who had been under LT4 suppressive therapy for at least 2 years and who had had stable TSH levels of $0.1-0.4 \mu \mathrm{U} / \mathrm{ml}$ for at least two measurements prior to and during the study, was that even the mild suppression of TSH to $0.1-0.4 \mu \mathrm{U} / \mathrm{ml}$ with longterm LT4 therapy may cause cardiac alterations characterized by increased myocardial mass, diastolic dysfunction and impaired exercise capacity that can be partially improved by a $\beta$-adrenergic blockade.

The present data showed a striking impairment of LV filling in the patients with mildly suppressed TSH levels between 0.1 and $0.4 \mu \mathrm{U} / \mathrm{ml}$ as well as in the patients with significantly suppressed TSH levels. Impairment in both early components (IVR and $\mathrm{E}$ wave) and the late phase of diastole (A wave) were detected. These data support the presence of an abnormality in diastolic function involving myocardial ability to actively relax, as well as the the passive elasticity of the ventricle. Since myocardial hypertrophy directly determines the latter it seems that these alterations resulted from the increase in LV mass in our patients. LV mass was found to be increased in our patients and both early and late diastolic filling were correlated with the ventricular mass.

The cardiac effects of long-term LT4 suppressive TSH therapy have been studied previously in patients who had significantly suppressed TSH levels (14-18). In these studies it was shown that chronic exposure to a mild excess of thyroid hormones was responsible for the increase in $\operatorname{LV}$ mass $(14,18)$. Significant correlation between the duration of TSH-suppressive therapy and LV mass has also been reported (16). Diastolic dysfunction, which was observed in such patients, was suggested to be a consequence of increased LV mass $(16,17)$. An improvement in diastolic function was reported in patients with overt hyperthyroidism (28). Such a finding in patients who have much higher thyroid hormone levels than patients who are taking LT4 may be seen as a conflict. But, in contrast to the patients who were under suppressive doses of LT4 therapy, the patients with hyperthyroidism were not usually exposed to high levels of thyroid hormones for a long period. Patients receiving TSH-suppressive treatment show mild but prolonged elevation of thyroid hormone concentration $(10,12)$. In these patients, the heart undergoes functional as well as structural modifications (14). The patients in the present study showed significantly elevated FT4 levels compared with controls which suggested that these patients were actually thyrotoxic even though they had mildly suppressed TSH values.

$\beta$-blockade improved ventricular filling in the present patient group. Although $\beta$-blocking drugs have no direct beneficial effect on myocardial relaxation they may exert several other effects, including regression of ventricular hypertrophy (20). Improvement in the IVR, E waves and A waves with $\beta$-blockade in the present study might be due to the decrease in LVMI, although it was not statistically significant, probably because of the small number of patients in the study group and the short duration of treatment with the $\beta$-adrenergic blocking drug.

The reduction of the LV functional reserve in our patients was associated with a severe impairment of their exercise capacity. This was shown by the shorter

Table 5 Exercise capacity parameters in the study group $(n=12)$ before and after adrenergic $\beta$-blockade. Values are means \pm S.D.

\begin{tabular}{lccc}
\hline & $\begin{array}{c}\text { Before } \\
\end{array}$ & After \\
& $\mathrm{LT} 4, \mathrm{TSH} 0.1-0.4 \mu \mathrm{U} / \mathrm{ml}$ & $\mathrm{LT} 4+$ atenolol, TSH 0.1-0.4 $\mu \mathrm{U} / \mathrm{ml}$ & \\
\hline Resting & & & \\
Heart rate (beat/min) & $88 \pm 5$ & $66 \pm 3$ & $<0.005$ \\
Systolic blood pressure (mmHg) & $126 \pm 17$ & $111 \pm 8$ & $<0.005$ \\
Diastolic blood pressure (mmHg) & $81 \pm 6$ & $71 \pm 5$ & $<0.008$ \\
Maximal exercise & $167 \pm 7$ & $140 \pm 3$ & $<0.01$ \\
Heart rate (beats/min) & $153 \pm 16$ & $121 \pm 8$ & $<0.005$ \\
Systolic blood pressure (mmHg) & $85 \pm 4$ & $77 \pm 4$ & $<0.007$ \\
Diastolic blood pressure (mmHg) & $87 \pm 23$ & $111 \pm 19$ & $=0.0079$ \\
Work load (W) & $7 \pm 1.89$ & $8.6 \pm 1.6$ & $=0.007$ \\
Exercise time (min) & & & \\
\hline
\end{tabular}


duration and peak work load observed during maximal physical exercise. The distorted diastolic filling may be an explanation for the impaired exercise capacity on effort in our patients. Diastolic dysfunction can cause heart failure and affect exercise capacity (20, 25). Biondi et al. (17) have reported impaired exercise capacity in patients who were under LT4 suppressive therapy. However, one should remember that thyroid hormone excess may also cause skeletal muscle abnormalities, which might also decrease exercise capacity (29). Since adrenergic $\beta$-blockade improves skeletal muscle weakness too, no matter what the cause, the addition of a $\beta$-blocking drug will definitely improve the physical exercise capacity.

Despite having some limitations, such as the small number of the patients studied and the non-randomized design, we believe that the observation of cardiac alterations even in patients with mild TSH suppression and the beneficial effects of $\beta$-blockade provides a rationale for instituting a combined therapy. It seems that, regardless of the degree of TSH suppression, addition of a $\beta$-blocking agent to the LT4 therapy may be beneficial. Our data also raise additional concern about long-term TSH-suppressive therapy in patients with nodular or diffuse goiter in whom there is uncertainty about a beneficial effect on thyroid size. However in iodine-deficient areas there is a decrease in thyroid nodule size and no new nodule formations were reported $(30,31)$. LT4 suppressive therapy may be recommended under such circumstances. Suppression of TSH to the level of $0.1-0.4 \mu \mathrm{U} / \mathrm{ml}$ is also required in patients with differentiated thyroid carcinoma with low risk $(32,33)$. TSH suppression improves survival in such patients and LT4 treatment is essential. Since long-term exposure to high levels of thyroid hormone may cause cardiac dysfunction we suggest that these patients should be monitored more carefully.

In conclusion, since diastolic dysfunction can cause a deterioration in cardiac performance and cardiac insufficiency, the preservation of the diastolic function is important in patients who should have TSH-suppressive therapy, no matter what the degree of suppression is. Addition of a $\beta$-adrenergic blocking drug to LT4 suppressive therapy improves diastolic dysfunction in patients and should be taken into consideration when long-term TSH suppression is necessary.

\section{Acknowledgements}

This study was presented as a poster (oral discussion) at the 12th International Thyroid Congress 2000, Kyoto, Japan.

\section{References}

1 Biondi B, Palmieri EA, Lombardi G \& Fazio S. Effects of thyroid hormone on cardiac function: the relative importance of rate, loading conditions, and myocardial contractility in the regulation of cardiac performance in human hyperthyroidism. Journal of Clinical Endocrinology and Metabolism 2002 87 968-974.

2 Klein I \& Ojamaa K. Thyroid hormone and the cardiovascular system. New England Journal of Medicine 2001344 501-509.

3 Klein I \& Ojamaa K. Thyroid hormone - targeting the heart. Endocrinology $200114211-12$.

4 Toft AD \& Boon NA. Thyroid disease and the heart. Heart 2000 84 455-460.

5 Fadel BM, Ellahham S, Ringel MD, Lindsay J Jr, Wartofsky L \& Burman KD. Hyperthyroid heart disease. Clinical Cardiology $200023402-408$.

6 Klein I. Thyroid hormone and the cardiovascular system. American Journal of Medicine $1990 \mathbf{8 8} 631-637$.

7 Ladenson PW. Recognition and management of cardiovascular disease related to thyroid dysfunction. American Journal of Medicine $1990 \mathbf{8 8} 638-641$.

8 Dillmann WH. Biomedical basis of thyroid hormone action in the heart. American Journal of Medicine 199088 626-630.

9 Polikar R, Burger AG, Scherrer U \& Nicod P. The thyroid and the heart. Circulation 199387 1435-1441.

10 Mandel SJ, Brent GA \& Larsen PR. Levothyroxine therapy in patients with thyroid disease. Annals of Internal Medicine 1993 $119492-502$.

11 Gharib H \& Mazzaferri EL. Thyroxine suppressive therapy in patients with nodular thyroid disease. Annals of Internal Medicine 1998128 386-394.

12 Ross DS. Subclinical hyperthyroidism: possible danger of overzealous thyroxine replacement therapy. Mayo Clinics Proceedings $1988631223-1229$.

13 Banovac K, Papic M, Bilsker MS, Zakarija M \& McKenzie JM. Evidence of hyperthyroidism in apparently euthyroid patients treated with levothyroxine. Archives of Internal Medicine 1989149 809-812.

14 Biondi B, Fazio S, Carella C, Amato G, Cittadini A, Lupoli G et al. Cardiac effects of long term thyrotropin-suppressive therapy with levothyroxine. Journal of Clinical Endocrinology and Metabolism $199377334-338$.

15 Biondi B, Fazio S, Carella C, Sabatini D, Amato G, Cittadini A et al. Control of adrenergic overactivity by $\beta$-blockade improves the quality of life in patients receiving long-term suppressive therapy with levothyroxine. Journal of Clinical Endocrinology and Metabolism 199478 1028-1033.

16 Fazio S, Biondi B, Carella C, Sabatini D, Cittadini A, Panza N et al. Diastolic dysfunction in patients on thyrotropin-suppressive therapy with levothyroxine: beneficial effect of $\beta$-blockade. Journal of Clinical Endocrinology and Metabolism $1995 \mathbf{8 0} 2222-2226$.

17 Biondi B, Fazio S, Cuocolo A, Sabatini D, Nicolai E, Lombardi G et al. Impaired cardiac reserve and exercise capacity in patients receiving long-term thyrotropin suppressive therapy with levothyroxine. Journal of Clinical Endocrinology and Metabolism $1996814224-4228$.

18 Mercuro G, Panzuto MG, Bina A, Leo M, Cabula R, Petrini L et al. Cardiac function, physical exercise capacity and quality of life during long-term thyrotropin-suppressive therapy with levothyroxine: effect of individual tailoring. Journal of Clinical Endocrinology and Metabolism 200085 159-164.

19 Shapiro LE, Sievert R, Ong L, Ocampo EL, Chance RA, Lee M et al. Minimal cardiac effects in asymptomatic athyreotic patients chronically treated with thyrotropin-suppressive doses of L-thyroxine. Journal of Clinical Endocrinology and Metabolism $1997 \mathbf{8 2}$ $2592-2595$.

20 Bonow RO \& Udelson JE. Left ventricular diastolic dysfunction as a cause of congestive heart failure. Annals of Internal Medicine 1992 $117502-509$.

21 van Kraaij DJ, van Pol PE, Ruiters AW, de Swart JB, Lips DJ, Lencer $\mathrm{N}$ et al. Diagnosing diastolic heart failure. European Journal of Heart Failure $2002 \mathbf{4} 419-430$.

22 Smiseth OA. Assessment of ventricular diastolic function. Canadian Journal of Cardiology 200117 1167-1176. 
23 Phillips RA \& Diamond JA. Diastolic function in hypertension. Current Cardiology Reports 20013 485-497.

24 Maniu CV \& Redfield MM. Diastolic dysfunction: insights into pathophysiology and pharmacotherapy. Expert Opinion on Pharmacotherapy 20012 997-1008.

25 de Simone G \& Palmieri V. Diastolic dysfunction in arterial hypertension. Journal of Clinical Hypertension 20013 22-27.

26 Sahn DJ, DeMaria AN, Kisslo J \& Weymen AE. Recommendation regarding quantitation in M-Mode echocardiography: results of a survey of echocardiographic measurements. Circulation 1978 5 1072-1083.

27 Devereux RB \& Reichek N. Echocardiographic determination of left ventricular mass in man. Circulation 197755 1441-1446.

28 Minz G, Pizzarello R \& Klein I. Enhanced left ventricular diastolic function in hyperthyroidism: noninvasive assessment and response to treatment. Journal of Clinical Endocrinology and Metabolism 199173 146-150.

29 Olson BR, Klein I, Benner R, Burdett R, Trzepacz P \& Levey GS. Hyperthyroid myopathy and response to treatment. Thyroid $19911137-141$.
30 Papini E, Petrucci L, Guglielmi R, Panunzi C, Rinaldi R, Bacci V et al. Long-term changes in nodular goiter: a 5-year prospective randomized trial of levothyroxine suppressive therapy for benign cold thyroid nodules. Journal of Clinical Endocrinology and Metabolism $1998 \mathbf{8 3} 780-783$.

31 Gullu S, Gurses MA, Baskal N, Uysal AR, Kamel AN \& Erdogan G. Suppressive therapy with levothyroxine for euthyroid diffuse and nodular goiter. Endocrine Jounal 199946 221-226.

32 Ozata M, Suzuki S, Miyamoto T, Liu RT, Fierro-Renoy F \& DeGroot LJ. Serum thyroglobulin in the follow-up of patients with treated differentiated thyroid cancer. Journal of Clinical Endocrinology and Metabolism 199479 98-105.

33 Kamel N, Gullu S, Dagci Ilgin S, Corapcioglu D, Tonyukuk Cesur $\mathrm{V}$, Uysal AR et al. Degree of thyrotropin suppression in differentiated thyroid cancer without recurrence or metastases. Thyroid $199991245-1248$.

Received 5 November 2003 Accepted 2 February 2004 